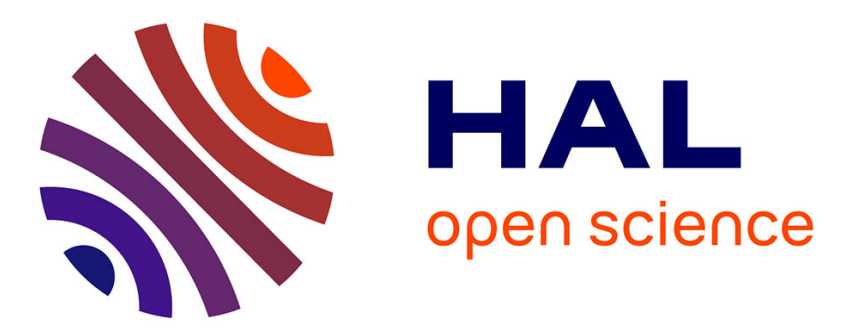

\title{
Complex Pt/Al2O3 materials for small catalytic systems
} Christos Christoglou, Pierre Alphonse, Claude Armand, Christophe Desnoyer, Constantin Vahlas

\section{To cite this version:}

Christos Christoglou, Pierre Alphonse, Claude Armand, Christophe Desnoyer, Constantin Vahlas. Complex Pt/Al2O3 materials for small catalytic systems. Surface and Coatings Technology, 2007, vol. 201, pp. 9195-9199. 10.1016/j.surfcoat.2007.04.101 . hal-00808904

\section{HAL Id: hal-00808904 https://hal.science/hal-00808904}

Submitted on 8 Apr 2013

HAL is a multi-disciplinary open access archive for the deposit and dissemination of scientific research documents, whether they are published or not. The documents may come from teaching and research institutions in France or abroad, or from public or private research centers.
L'archive ouverte pluridisciplinaire HAL, est destinée au dépôt et à la diffusion de documents scientifiques de niveau recherche, publiés ou non, émanant des établissements d'enseignement et de recherche français ou étrangers, des laboratoires publics ou privés. 


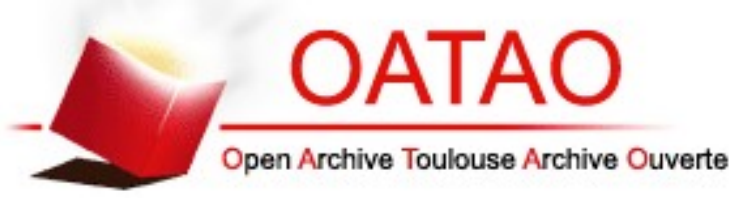

\section{Open Archive Toulouse Archive Ouverte (OATAO)}

OATAO is an open access repository that collects the work of Toulouse researchers and makes it freely available over the web where possible.

This is an author-deposited version published in: http://oatao.univ-toulouse.fr/ Eprints ID : 2445

To link to this article :

URL : http://dx.doi.org/10.1016/j.surfcoat.2007.04.101

To cite this version : Christoglou, Christos and Alphonse, Pierre and Armand, Claude and Desnoyer, Christophe and Vahlas, Constantin ( 2007) Complex Pt/Al2O3 materials for small catalytic systems. Surface and Coatings Technology, vol. 201 (n 22 - 23). pp. 9195-9199. ISSN 0257-8972

Any correspondence concerning this service should be sent to the repository administrator:staff-oatao@inp-toulouse.fr 


\title{
Complex Pt/ $/ \mathrm{Al}_{2} \mathrm{O}_{3}$ materials for small catalytic systems
}

\author{
Christos Christoglou ${ }^{\mathrm{a}}$, Pierre Alphonse ${ }^{\mathrm{b}}$, Claude Armand ${ }^{\mathrm{c}}$, \\ Christophe Desnoyer ${ }^{\mathrm{d}}$, Constantin Vahlas ${ }^{\mathrm{a}, *}$

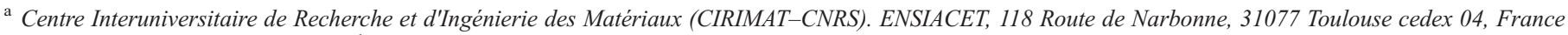 \\ ${ }^{\mathrm{b}}$ CIRIMAT-CNRS, Université Paul Sabatier, Bât.2R1, 31062 Toulouse cedex 9, France \\ ' Département de Physique, INSA, 135 av. de Rangueil, 31077 Toulouse cedex 04, France \\ ${ }^{\mathrm{d}}$ SOLEA SAS, Zone Industrielle Estarac, 31360 Boussens, France
}

\begin{abstract}
This paper reports on the preparation of catalytic materials composed of a porous metallic preform containing winding microchannels whose surface is coated by a complex catalytic film. $\mathrm{Al}_{2} \mathrm{O}_{3}$ is deposited inside the pores by means of wet impregnation in a first step, in order to increase the surface and to serve as an intermediate layer on which Pt nanoparticles are deposited in a second step. The latter deposition takes place by means of forced metalorganic chemical vapour infiltration (F-MOCVI). Pt(acac) $)_{2}$, is used in appropriate low pressure operating conditions, to allow for a process with low thermal budget, compatible with the geometrical and physical characteristics of the porous substrate. The results are evaluated by means of BET, SIMS, SEM/EDX and FEG/SEM. The catalytic material is finally being tested following the oxidation of carbon monoxide, a model reaction with high industrial interest.
\end{abstract}

Keywords: Chemical vapour infiltration; Alumina; Platinum; Nanoparticles; Catalysis; Carbon monoxide

\section{Introduction}

Catalysts have an enormous impact on the chemical industry and every-day applications, with the catalysis industry being the largest single economic activity today [1]. High catalytic activity induces either high productivity from relatively small reactors or mild operating conditions. Catalyst preparation is the secret to achieving the desired activity, selectivity and lifetime. The activity of solid catalysts is proportional to the active surface area per unit volume of catalyst. This consequently calls for small catalytic particles. The high reactivity of nanoparticles makes them good candidates for environmental catalysts for the treatment of automotive exhaust [2]. Preparation of large quantities of heterogeneous materials containing monodispersed nanoparticles is becoming one of the bottlenecks that hinder the development of industrial devices [3]. In most cases, the catalysts are being supported by a highly porous and thermally stable material, onto which the active species are being dispersed. The main purpose of

\footnotetext{
* Corresponding author. Tel.: +33 562885 670; fax: +33 562885600 .

E-mail address: Constantin.Vahlas@ensiacet.fr (C. Vahlas).
}

a support is to achieve an optimal dispersion of the catalytically active component(s) and to stabilize it/them against sintering. The most rapid procedure to prepare catalysts of such type is to start from commercially available preshaped support materials of the desired size, shape, porosity and mechanical properties. Applying the active element finely on the support, leads to the final material. Alumina is a widely used support body since it is a hard material with an excellent chemical stability [4]. Pt is an ideal catalytic active material. The use of metalorganic complexes as precursors of supported metal catalysts provides an important way to prepare highly dispersed and selective catalysts [5-9].

The present work deals with the preparation of a complex catalytic material for use in small catalytic systems. It consists of a commercially available metallic disk shaped preform of specific pore size and porosity. Alumina was deposited inside the pores via wet impregnation to increase the surface area and to serve as anchoring sites for the subsequent deposition of $\mathrm{Pt}$ particles. Platinum was deposited via forced metalorganic chemical vapour infiltration (F-MOCVI) in a hot-wall reactor, starting from platinum bis-acetylacetonate precursor, $\mathrm{Pt}(\mathrm{acac})_{2}$. The obtained catalytic material is finally being tested following 


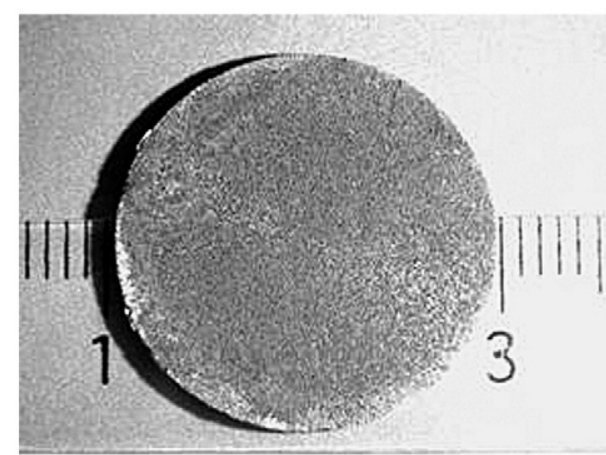

Fig. 1. Optical micrograph of the as-delivered porous preform.

the oxidation of carbon monoxide, a model reaction with high industrial interest.

\section{Experimental procedure}

The substrates consist of $1 \mathrm{~mm}$ thick and $19 \mathrm{~mm}$ diameter porous disks shown in Fig. 1. They are commercialized by SOLEA SAS. Different copper and 316 stainless steel porous disks, whose pore size and porosity vary from $20 \mu \mathrm{m}$ to $100 \mu \mathrm{m}$ and $50 \%$ to $70 \%$ respectively, were used. Copper disks were used as substrate for the secondary ion mass spectrometry (SIMS) analysis because such analysis is difficult on the complex surface of the stainless steel porous substrates. Wherever the medium pore size is mentioned, it should be taken into consideration that micropores of significantly smaller size coexist.

\subsection{Alumina deposition}

In the first deposition step, the porous disks are immerged under vacuum in a $1 \mathrm{M}$ boehmite (Disperal P2, Sasol, Gmbh) dispersion solution with addition of $10 \%$ alcohol. They are left to dry in air overnight and subsequently heated at $450^{\circ} \mathrm{C}$ for $4 \mathrm{~h}$. The latter step allows the transformation of boehmite into alumina [10]. The weight of the deposited alumina was calculated by weight difference of the samples before and after the process. The overall surface of each porous disk and the efficiency of the alumina coating method were evaluated by Brunauer, Emett and Teller (BET) measurements with a Micrometritics ASAP2010M apparatus. At this stage, the catalytic activity of alumina-coated disks was measured considering the reaction of $\mathrm{CO}$ oxidation and was found to be close to zero. Taking into account (i) the non-negligible catalytic activity of as received $\mathrm{Cu}$ disks; (ii) the fact that pressure

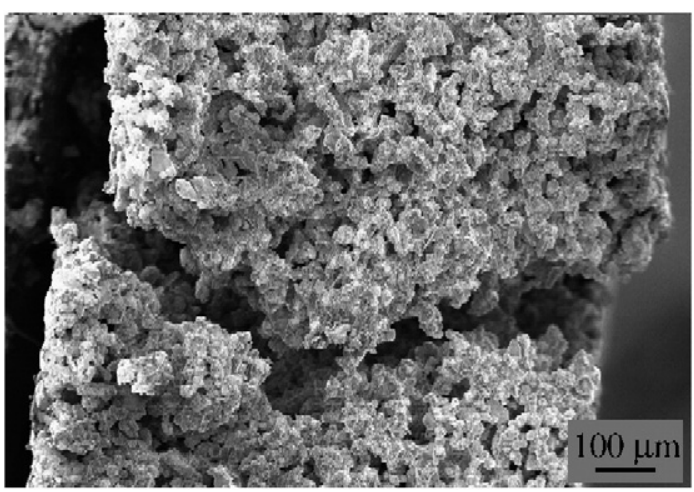

Fig. 3. SEM micrograph of the cross-section of stainless steel porous disk (100 $\mu \mathrm{m}$ pore size, $70 \%$ porosity) after wet impregnation of alumina film.

drop through the substrate during CVI remains unchanged and (iii) cross-section SEM observations, it is concluded that the substrate had been completely covered without significant pores blocking.

\subsection{Platinum deposition}

In the second deposition step, a hot-wall CVD reactor, depicted in Fig. 2 was used for the deposition of Pt particles inside the pores of the preforms. Pt(acac) $)_{2}$ (Acros Organics), a solid, air-stable and cost effective precursor was heated at ca. $155{ }^{\circ} \mathrm{C}$ under $\mathrm{N}_{2}$ flow and 50 Torr in the low temperature section of the reactor. The formed vapours were driven through a quartz tube at the end of which the porous disk was glued with a Ceramobond 596 paste-like glue. In this way the gases passed through the open porosity where Pt deposition was obtained by heating the disk at $390^{\circ} \mathrm{C}$. Flat samples of the same material as the porous disk (stainless steel or copper) were positioned shortly before and after the porous disk. Visual observation and X-ray photoelectron spectrometry (XPS) analyses on the flat samples were used as indication for the deposition of Pt inside the pores of the substrate. After the deposition step, the reactor was left to cool under $\mathrm{N}_{2}$ flow; then the disk was torn off the quartz tube. Because alumina paste had inevitably infiltrated radially some of the pores, a weight measurement to establish the weight of the deposited Pt was not used. Instead, Pt concentration was measured by Inductively Coupled PlasmaAtomic Emission Spectrometry (ICP-AES).

The evaluation of the catalytic activity of the disk was realized through the $\mathrm{CO}$ oxidation reaction with $1 \% \mathrm{CO}$ and $0.66 \% \mathrm{O}_{2}$ in Ar (total flow rate $110 \mathrm{~cm}^{3} / \mathrm{min}$ ). A detailed

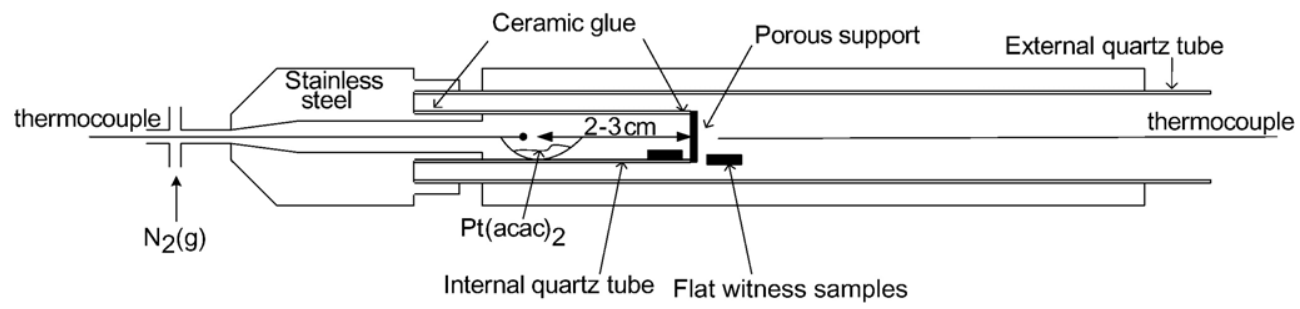

Fig. 2. Schematic representation of experimental set up for the F-MOCVI of Pt. 

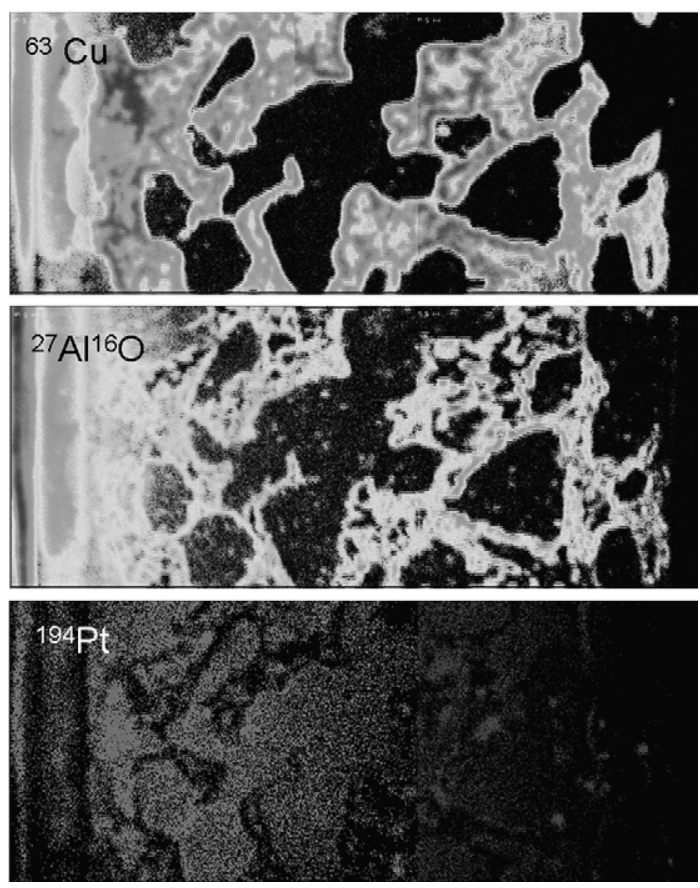

Fig. 4. Cross-section SIMS map throughout the thickness of a $\mathrm{Cu}$ disk (1 mm). The left side is the entrance of the reactive gas phase during Pt F-MOCVI. From top to bottom: $\mathrm{Cu}$ (substrate), alumina and Pt.

description of the procedure will be presented in a forthcoming paper. The disk was then examined by scanning electron microscopy (SEM) with a LEO $435 \mathrm{VP}$ and a field emission gun JEOL JSM6700F apparatuses, both equipped with X-ray energy dispersive spectroscopy (EDS) analyzers. Transmission electron microscopy (TEM) imaging was performed with a Jeol JEM-2010 microscope operating at $200 \mathrm{kV}$ equipped with a Tracor EDS analyzer. TEM analysis was used to examine the Pt particles size and distribution. SIMS was performed with a
CAMECA IMS4F6 apparatus for the cross-section elements mapping.

\section{Results and discussion}

Alumina deposition leads to the increase of the specific surface area of the porous stainless steel preform from ca. $1 \mathrm{~m}^{2} / \mathrm{g}$ up to $15 \mathrm{~m}^{2} / \mathrm{g}$. Although this is a substantial increase, it reveals that an alumina film deposited on a complex microporous surface provides lower specific surface area than that a whole alumina preform can reach, which is up to $150 \mathrm{~m}^{2} / \mathrm{g}$ and sometimes $300 \mathrm{~m}^{2} /$ $\mathrm{g}[11,12]$. The weight of the deposited alumina is less than $0.02 \mathrm{~g}$ in all cases. Fig. 3 presents a SEM micrograph of the cross-section of stainless steel porous disk ( $100 \mu \mathrm{m}$ pore size, $70 \%$ porosity) after wet impregnation of alumina film. It can be observed that the pores remain open. This result, combined with systematic detection of the aluminium element by EDX indicates deposition of a uniform alumina coating.

SIMS observation of the infiltrated alumina and Pt is more convenient on copper than on stainless steel preforms due to the numerous peaks and possible interferences for the latter. For this reason, similar copper samples (100 $\mu \mathrm{m}$ pore size, $70 \%$ porosity) as the stainless steel ones were impregnated with alumina and subsequently processed by F-MOCVI for the deposition of Pt nanoparticles. Fig. 4 depicts the cross-section of such a disk. Pt deposition was performed in the previously mentioned conditions for $60 \mathrm{~min}$. Homogeneous coverage of the surface of the pores with alumina can be observed, confirming the SEM/EDX observations. In contrast, Pt distribution is uneven over the cross-section, deposition being mainly located near the gas entrance surface. These results were confirmed by SEM/EDX analysis which revealed that Pt existed over a significant percentage of the whole area of the cross-section, but was absent at the exit side of the disk, while alumina was present everywhere. Decreasing deposition temperature and consequently the growth rate did not allow

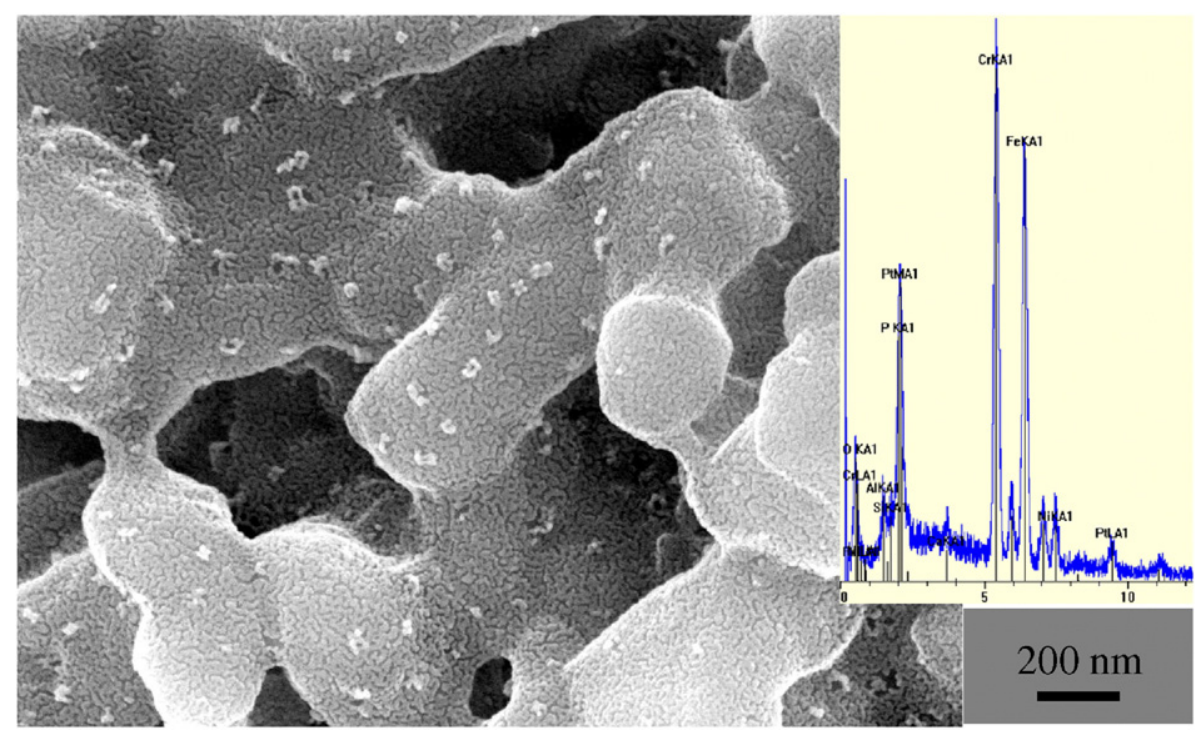

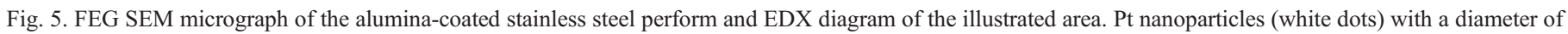
approximately $20 \mathrm{~nm}$ are distributed over the alumina layer. 


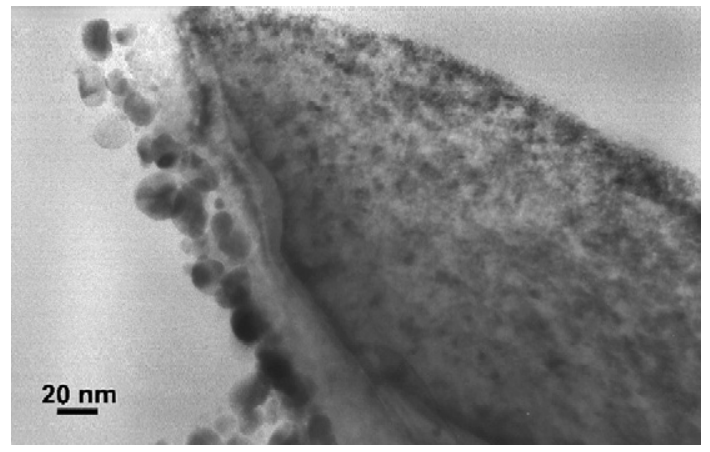

Fig. 6. Bright field TEM micrograph of Pt nanoparticles deposited on the pores of the stainless steel preform.

improvement of the distribution of Pt due to the autocatalytic behaviour of Pt deposition.

A stainless steel disk of identical geometrical characteristics as those of the copper disk was processed in the same conditions for the deposition of alumina and Pt. Its specific surface area was measured after the alumina deposition and was found to be $5 \mathrm{~m}^{2} / \mathrm{g}$. The sample was tested for its catalytic activity with regard to the oxidation of CO. An exceptionally high value of $4.5 \mathrm{Pt}$ wt.\% was found, possibly due to stream lines pattern prior the substrate, leading to the enhanced growth rate at the central part of the disk. Fig. 5 presents a FEG SEM micrograph of the central part of the disk. Pt nanoparticles, illustrated as bright white spots can be observed over an evenly distributed alumina layer. EDX analysis of this area reveals intense Pt peaks. Observation of areas at the extreme periphery of the disk and corresponding EDX analysis do not reveal the presence of Pt. It is concluded that Pt radial distribution on the disk is not uniform, its central area being richer in Pt than its periphery. Fig. 6 presents a bright field TEM micrograph of the central part of this sample. Numerous Pt nanoparticles are shown whose maximum size is approximately $20 \mathrm{~nm}$. This value is compatible with the one observed in Fig. 5 and with that reported by other researchers [13].

In order to decrease the Pt loading of the disks, a stainless steel porous disk with $70 \%$ porosity and $60 \mu \mathrm{m}$ mean pores size was processed in the same conditions but with a 10 min instead of $60 \mathrm{~min}$ for the F-MOCVI of Pt. The weight of the wet impregnated alumina was found to be $0.0112 \mathrm{~g}$ yielding a specific surface area of this porous disk $15 \mathrm{~m}^{2} / \mathrm{g}$. The resulting Pt concentration was determined to be $\sim 0.3 \mathrm{wt} . \%$; i.e. significantly lower than that of the previous sample. Pt was traced in the cross-section of the pores by FEG SEM, but no nanoparticles were visible as shown in the FEG SEM micrograph of Fig. 7 where only the alumina film can be observed. However, EDX analysis revealed intense Pt peaks as for the previous sample, indicating the extremely dispersed nanostructure of $\mathrm{Pt}$.

The catalytic activity of the coated disks was investigated through the $\mathrm{CO}$ to $\mathrm{CO}_{2}$ conversion. Tests performed as a function of temperature on the two mentioned stainless steel disks and on asdelivered stainless steel disks and on alumina-coated ones. Both latter samples show no catalytic activity. The two Pt loaded samples show similar catalytic behaviour with T50 $(50 \%$ conversion temperature) values $209{ }^{\circ} \mathrm{C}$ and $203{ }^{\circ} \mathrm{C}$ for the heavily and lightly loaded sample, respectively. This temperature is common for such catalysts, similar activity being reported by other researchers who have produced $\mathrm{Pt} / \mathrm{Al}_{2} \mathrm{O}_{3}$ catalysts by various methods such as $\mathrm{CVD}$ or wet impregnation $[11,12,14-16]$. The comparable behaviour of the two samples despite their different Pt loading is attributed to the size of the Pt nanoparticles. High Pt loading corresponds to large Pt

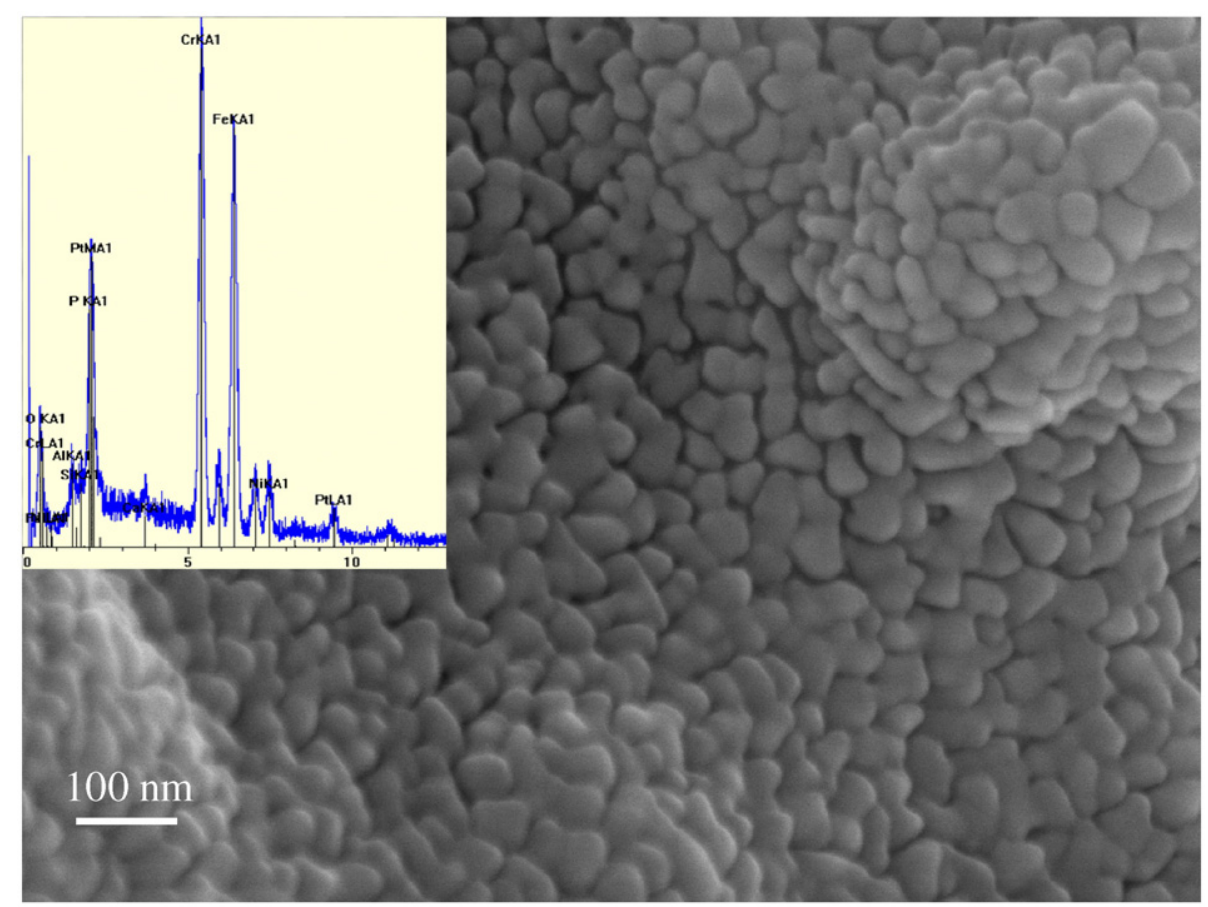

Fig. 7. FEG SEM micrograph of stainless steel preform coated with alumina and Pt nanoparticles of reduced size. The Pt particles cannot be seen, but EDX analysis of the illustrated area reveals intense Pt peaks. 
particles, while lower Pt loading corresponds to more finely dispersed Pt nuclei. These two different configurations may ultimately result in comparable active surface sites.

\section{Conclusions}

Catalytic materials were prepared starting from commercially available porous disk shaped performs. Alumina was first deposited by wet impregnation, a convenient and time efficient technique yielding a homogeneous distributed coating on the entire surface of the pores. The alumina films induced a 5 to 15 fold increase of the specific surface area of the disks. They also created appropriate anchoring sites for the subsequent Pt particles deposition. This was performed by means of forced metalorganic chemical vapour infiltration starting from $\mathrm{Pt}(\mathrm{acac})_{2}$, an air-stable and cost effective precursor. Pt concentration is higher at the entrance side of the disk and at its central part. The size of $\mathrm{Pt}$ nanoparticles was kept under $20 \mathrm{~nm}$. Shorter Pt deposition time on higher specific surface alumina yields lower and more finely dispersed Pt loading of the disks. The catalytic activity of the processed samples was evaluated by using the model through a technologically interesting reaction of $\mathrm{CO}$ oxidation staring from an $\mathrm{O}_{2}$ to $\mathrm{CO}$ ratio equal to 0.66 . The $\mathrm{T}_{50}$ was found to be slightly above $200^{\circ} \mathrm{C}$. It is expected that the increase of the specific surface area of the alumina coating will allow more finely dispersed (and consequently more efficient) $\mathrm{Pt}$ deposition and ultimately improvement of the catalytic performance of this material.

\section{Acknowledgments}

We are indebted to Marie Christine Lafont and to Djar Oquab for the preparation and observation of TEM cross-sections and for the operation of the FEG SEM, respectively. This work was performed through a Marie Curie Individual Fellowship (grant number MEIF-CT-2005-006817) accorded to CC by the European Commission. The support of the French Midi-Pyrenees region though grant \#03012429 is also acknowledged.

\section{References}

[1] K.P. de Jong, Cat. Tech. 3 (1998) 87.

[2] P. Gorišek, V. Francetič, C.L. Lengauer, J. Maček, Acta Chim. Slov. 51 (2) (2004) 203.

[3] J.A. Aboaf, J. Electrochem. Soc. 114 (1967) 948.

[4] S.K. Pradhan, J. Reucroft, Y. Ko, Surf. Coat. Technol. 176 (2004) 382.

[5] Yu.I. Yermakov, Catal. Rev., Sci. Eng. 13 (1976) 77.

[6] P. Serp, J.C. Hierso, Carbon 37 (1999) 527.

[7] T. Goto, R. Vargas, T. Hirai, J. de Physique IV (2) (1993) 297.

[8] M.J. Rand, J. Electrochem. Soc. 120 (1973) 686.

[9] M. Womes, T. Cholley, F. Le Peltier, S. Morin, B. Didillon, N. SzydlowskiSch, Appl. Catal., A Gen 283 (2005) 9.

[10] P. Alphonse, M. Courty, Thermochim. Acta, 425 (2005) 75.

[11] V. Meille, S. Pallier, G.V. Santa Cruz Bustamante, M. Roumanie, J.P. Reymond, Appl. Catal., A Gen 286 (2005) 232.

[12] S.H. Cho, J.S. Park, S.H. Choi, S.K. Lee, S.H. Kim, Catal. Lett. 103 (2005) 257.

[13] K. Arnby, A. Toerncrona, B. Andersson, M. Skoglundh, J. Catal. 221 (2004) 252.

[14] J.J. Carberry, S. Rajadurai, C.B. Alcock, Catal. Lett. 4 (1990) 43.

[15] J.A. Anderson, Catal. Lett. 13 (1992) 363.

[16] A.E. Aksoylu, J.L. Faria, M.F.R. Pereira, J.L. Figueiredo Serp, Appl. Catal., A Gen 243 (2003) 357. 